\title{
Heritability of morphological and life history traits in a pelagic tunicate
}

\author{
Carla M. Lobónn ${ }^{1}$, José L. Acuña ${ }^{1, *}$, Marcos López-Álvarez ${ }^{1}$, Fabiana L. Capitanioº \\ ${ }^{1}$ Departamento de Biología de Organismos y Sistemas, Universidad de Oviedo, Oviedo 33071, Spain \\ ${ }^{2}$ CONICET, Departamento de Ciencias Biológicas, Facultad de Ciencias Exactas y Naturales, Universidad de Buenos Aires, \\ C 1428 EHA Buenos Aires, Argentina
}

\begin{abstract}
Populations may adapt in response to selection pressures imposed by global environmental change. In marine zooplankton, measurements of the heritability of key life history characters, and thus the potential for evolution, are still rare. Here we demonstrate the feasibility of conducting controlled mating experiments with the dioecious appendicularian Oikopleura dioica to explore the narrow-sense heritability and genetic correlation among morphological and life history traits. At our standard laboratory conditions $\left(15 \pm 1^{\circ} \mathrm{C}, 100 \mu \mathrm{g} \mathrm{C}{ }^{-1}\right)$, mature females were larger $(1.213 \pm 0.19 \mathrm{~mm}$, mean $\pm \mathrm{SD})$ and lived longer $(8.5 \pm 2.18 \mathrm{~d})$ than did males $(1.115 \pm 0.15 \mathrm{~mm}, 7.6 \pm$ $2.07 \mathrm{~d}$ ). The heritability ( \pm SE) of morphological characters was low (trunk size, $0.37 \pm 0.25$; house size, $0.39 \pm 0.23$ ) to moderate (tail length, $0.50 \pm 0.31$ ). In contrast, an important life history trait, lifespan, showed high heritability $(0.89 \pm 0.47)$ and may therefore respond rapidly to selection pressure, either in the laboratory or in the wild.
\end{abstract}

KEY WORDS: Life history traits $\cdot$ Individual variability $\cdot$ Heritability $\cdot$ Oikopleura dioica

\section{INTRODUCTION}

There is accumulating evidence of shifts in the distribution and phenology of plankton communities, most probably in response to global warming (e.g. Beaugrand et al. 2002, deYoung et al. 2004, Richardson \& Schoeman 2004, Hays et al. 2005). These shifts may potentially lead to mismatches in the life cycle of interacting species with consequences on the productivity and biodiversity of marine ecosystems (e.g. between fish and their plankton food, Cushing 1990, Ottersen et al. 2001, Beaugrand et al. 2003). The new distributions result from an equilibrium between dispersal ability, physiological adjustment and/or evolutionary adaptation to the new conditions (Gienapp et al. 2008). But just how much of the response is due to evolution remains a great mystery because the documented responses are often based on nongenetic data (Gienapp et al. 2008). This is an important issue, since physiological adjustment or phenotypic plasticity are fast, but limited, while the slow evolutionary process has broader limits and allows for an efficient, specialized response to new environmental conditions.

The microevolutionary process requires the existence of variance in a phenotypic trait on which selection will operate through fitness differences of the underlying genotypes. The strength of selection will depend on the heritability of that trait, that is, on the strength with which that trait is passed from parents to offspring, or the degree of resemblance between parents and offspring for that particular trait (Falconer \& Mackay 1996). The variability and heritability of different phenotypic traits has been studied in several marine organisms, with particular emphasis on economically relevant species, because they indicate the potential for genetic improvement through artificial selection (e.g. Sheridan 1997, Charo-Karisa et al. 2006, Neira et al. 2006). Quantitative genetic studies on zooplankton have focused mainly on freshwater organisms, like copepods (Wyngaard 1986a,b, Hairston \& Dillon 1990), and the clonal cladoceran Daphnia spp., one of the most widely used organisms for genetic and ecological stud- 
ies (e.g. Ebert et al. 1993, Spitze 1993). Only a few studies have focused on marine zooplanktonic species, most of them on copepods (McLaren 1976, Bradley 1978, McLaren \& Corkett 1978, Avery 2005).

Progress in understanding the evolutionary process is facilitated using short-lived, fecund, diploid organisms with small genomes (Mitchell-Olds 1995). The appendicularian Oikopleura dioica is a diploid, semelparous, marine pelagic tunicate that takes only 6 to $7 \mathrm{~d}$ to mature at $15^{\circ} \mathrm{C}$ (Sato et al. 2001, Troedsson et al. 2002), produces more than 300 eggs per female under suitable conditions (Troedsson et al. 2002) and has the smallest metazoan genome known (Seo et al. 2001). In contrast to the copepods, for which quantitative genetic information is available, appendicularians do not store lipid reserves (e.g. Troedsson et al. 2005), do not have dormancy stages and exhibit a highly opportunistic lifestyle characterized by marked population outbursts (up to 53000 individuals [ind.] $\mathrm{m}^{-3}$, Uye \& Ichino 1995). Unlike most copepods, appendicularians are true filter feeders that capture particles by means of a filter house, which is a delicate, external, mucous filtering apparatus. These organisms move the tail sinusoidally and periodically to pump a flow of water through the mucous filters (Fenaux 1986), which they renew every few hours (ca. $3 \mathrm{~h}$ at $15^{\circ} \mathrm{C}$ in laboratory conditions, Sato et al. 2001). Using this device, they trap food particles in the submicronic size range (Bedo et al. 1993), which is well below the typical food size range of most copepods. Appendicularians are eaten by many planktonic organisms (Gorsky \& Fenaux 1998, Sommer et al. 2003, López-Urrutia 2004) and are a significant food item for commercially important fishes (Capitanio et al. 2005, Purcell et al. 2005). Thus, they provide a shortcut in the food web by directly transferring energy from small particles to larger predators (Deibel 1998, Gorsky \& Fenaux 1998).

The appendicularian Oikopleura dioica can be cultured in the laboratory for several generations (Bouquet et al. 2009), thereby providing an opportunity to investigate the quantitative genetics of a marine zooplankton organism that are different from copepods in many important ecological respects, and phylogenetically closer to humans (Delsuc et al. 2006). The aim of the present study was to conduct a controlled mating experiment to determine the individual variability and heritability of important morphological and life history traits in $O$. dioica. This work is a first approximation to understand the genetic variation of an appendicularian population. In addition to sexual dimorphism, our study reveals a significant individual variability in traits that are closely related to fitness. We also showed that much of this variability has a genetic basis, thus these organisms are potentially susceptible to genetic selection, either in the laboratory or in the wild.

\section{MATERIALS AND METHODS}

Sampling and experimental conditions. Parental Oikopleura dioica for the experiments were collected on 23 April, 23 May and 12 October 2005 at the El Musel harbour in Gijón, northern Spain, by manually towing a WP2 net $(50 \mu \mathrm{m}$ mesh size, $40 \mathrm{~cm}$ mouth diameter) from the pier. Instead of using a large closed codend as advised for the collection of live appendicularians (e.g. Acuña et al. 1999), we used a conventional small codend with a filtering window, which can concentrate a large number of appendicularians. This more than compensates for losses due to damage during concentration within the codend. The contents of the codend were brought to a cold room set at $15 \pm 1^{\circ} \mathrm{C}$ with a simulated $12 \mathrm{~h}$ light: $12 \mathrm{~h}$ dark photoperiod. Healthy individual $O$. dioica inside filter houses were then transferred with wide bore pipettes to a 51 glass jar filled with $30 \mu \mathrm{m}$ filtered seawater containing 100 $\mu \mathrm{g} \mathrm{Cl}^{-1}$ of a mixture of Isochrysis galbana (Prymnesiophyte, $5 \mu$ m diameter, $10.6 \pm 0.3 \mathrm{pg} \mathrm{C}$ cell $^{-1}$; $70 \%$ by volume) and Chaetoceros calcitrans (Bacillariophyta, $3 \mu \mathrm{m}$ diameter and $5 \mu \mathrm{m}$ length, $4.6 \pm 0.3 \mathrm{pg} \mathrm{C}$ cell $^{-1}$; $30 \%$ by volume) (see Acuña \& Kiefer 2000 for details on phytoplankton culturing), which was continuously stirred by an acrylic spiral paddle rotating at $10 \mathrm{rpm}$ (Fenaux \& Gorsky 1985). O. dioica is a semelparous species that when mature breaks off and releases the gametes. An experienced observer can determine whether a mature or premature tunicate is male (yellowish gonad, Fig. 1d) or female (whitish gonad with a granulate texture due to the eggs, Fig.1a) and whether the organism is close to laying the gametes (swelling, large gonads). Once a sufficient number of mature organisms or those close to maturity appeared in the flask, they were picked and individually isolated in $0.25 \mathrm{l}$ glass jars filled with seawater filtered through a 0.8/0.2 $\mu \mathrm{m}$ pore-size capsule filter (Pall Acropak ${ }^{\mathrm{TM}}$ 1000 Sterile Capsules) and agitated with a glass paddle rotating at $10 \mathrm{rpm}$. These tunicates were allowed to spawn in the beakers, and the gametes were used for the mating experiment. All breeding experiments were conducted under the conditions mentioned above $\left(15 \pm 1^{\circ} \mathrm{C}, 12 \mathrm{~h}\right.$ light: $12 \mathrm{~h}$ dark photoperiod and $100 \mathrm{\mu g} \mathrm{Cl}^{-1}$ of algae).

Breeding design. We used a dam-sire, half-sib breeding design to examine the patterns of quantitative genetic variation of the traits studied (Roff 1997). In this design, one male (e.g. Male 1) is crossed with a number of females (e.g. Females 1, 2 and 3), another male (e.g. Male 2) is crossed with a number of other females (e.g. Females 4, 5 and 6), and so on. Thus, a series of half-sib families is produced. In our experiment, within $3 \mathrm{~h}$ of natural spawning, sperm of one male was used to fertilize eggs of 3 females, and the 


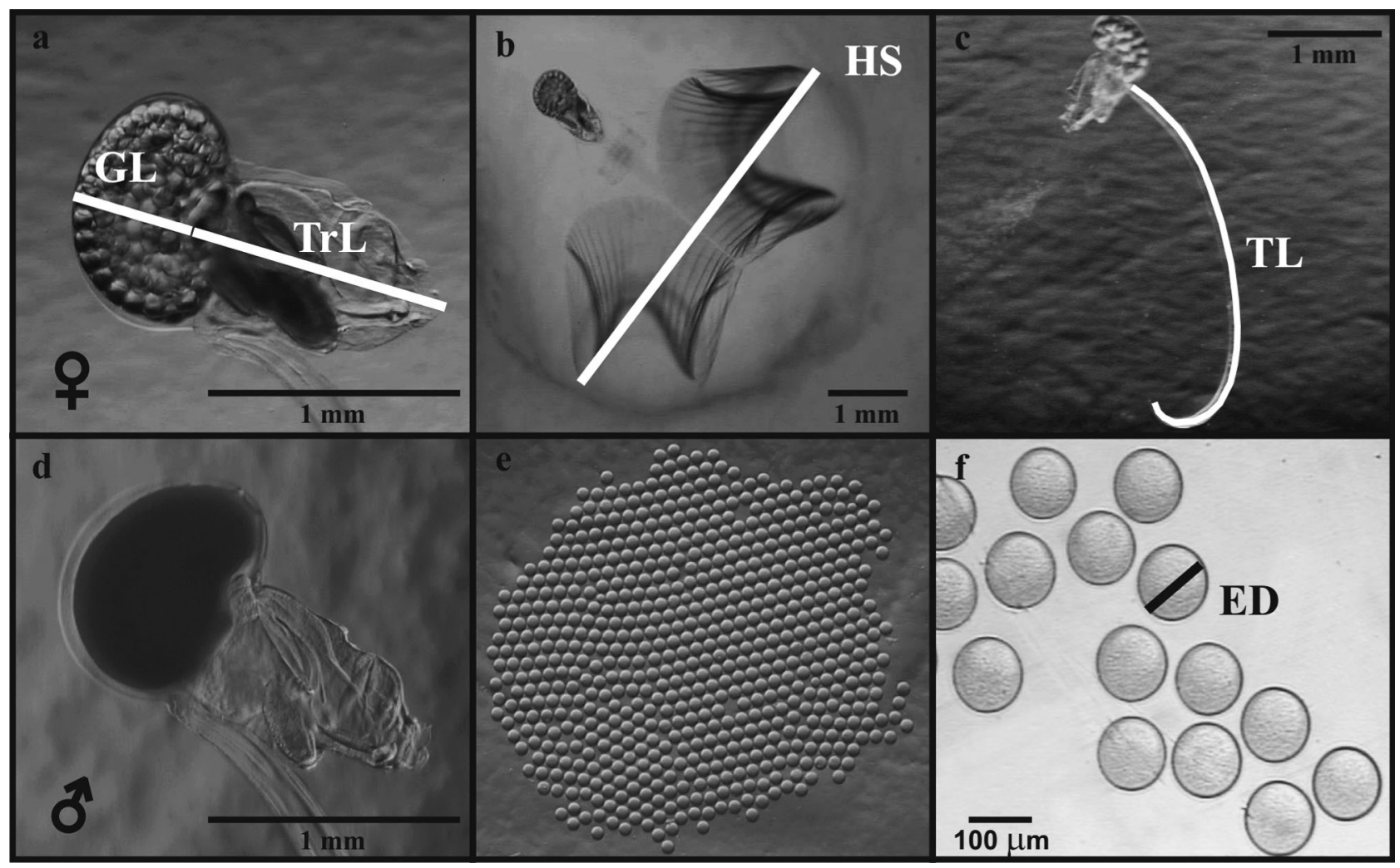

Fig. 1. Oikopleura dioica. (a-c) Mature females (d) male and (e,f) eggs from 1 female. Thick lines and letter codes indicate morphological measurements of the trunk length (TrL), gonad length (GL), tail length (TL), house size (HS) and egg diameter (ED)

time was recorded for further calculation of the lifespan. After fertilization, embryos of each full-sib family were transferred into $5 \mathrm{l}$ glass jars filled with $0.2 \mu \mathrm{m}$ filtered seawater and the 2 algae. This protocol was repeated for 13 sires (3 sampled on 23 April, Expt 1; 5 sampled on 23 May, Expt 2; 5 sampled on 12 October, Expt 3) for a total of 39 full-sib families. After $1 \mathrm{~d}$ of development, 10 appendicularians from each full-sib family were randomly selected and placed in a beaker. The animals were transferred to fresh, $0.2 \mu \mathrm{m}$ filtered seawater every day until maturation.

Measurements. Once the animals were close to maturity (i.e. not more than $6 \mathrm{~h}$ before spawning), they were photographed with a video camera (Leica IC A) mounted on a binocular microscope (Leica MZ 12.5) in combination with the MGI Video Wave SE Plus software. Morphology was determined with 4 measurements from the lateral view: trunk length, gonad length and tail length, as well as the sum of the trunk and gonad lengths to obtain the total body size. The size of the house was also estimated as the width or wingspan of the food concentrating filter in dorsal view (Fig. 1) after a small amount of Sepia ink was added to visualize the transparent feeding filter of the house (Flood et al. 1990).
After being measured, the animals were transferred separately to $20 \mathrm{ml}$ beakers and continuously monitored during night/day shifts until they spawned. The time was recorded to calculate the lifespan, and the eggs were recovered from the flasks and counted under a binocular microscope (Leica MZ 12 5) (Fig. 1e). The average diameter of 10 eggs per female was determined by means of an inverted microscope (Zeiss Axiovert 25) equipped with a video camera (Sony SSCC370P) and with MGI Video Wave SE Plus in combination with Image Pro Plus image analysis software (Fig. 1f).

In summary, we analyzed the following morphological traits: trunk length (TrL, mm; Fig. 1a), gonad length (GL, mm; Fig. 1a), tail length (TL, mm; Fig. 1c) and house size (HS, mm; Fig. 1b). The life history traits analyzed were: lifespan (L, days), clutch size (CS, number of eggs per female) and egg diameter (ED, mm; Fig.1f). Traits were log transformed to achieve normality and homogeneity of variances. For each individual female for which CS and L were available, we also estimated the maximal intrinsic rate of natural increase of Oikopleura dioica as:

$$
r_{\max }=\frac{\ln \mathrm{CS}}{\mathrm{L}}
$$


where $r_{\max }\left(\mathrm{d}^{-1}\right)$ can be taken as a measure of fitness in semelparous organisms without parental care such as O. dioica (Troedsson et al. 2002).

Data analysis. First, we tested the effect of experiment date by including in the model 'date' as a fixed factor with 3 levels (23 April, 23 May and 12 October). The other factors included were 'sire', random and nested within date (with 3,5 and 5 males for each date, respectively) and 'dam', random and nested within sire (with 3 females per male). Procedure 'Mixed' (SAS Institute) was used for all analyses using restricted maximum likelihood (REML) estimation (Littell et al. 1996), which is used instead of least squares estimation for unbalanced designs (Shaw 1987). Variables were log transformed for normalization. Estimated variance components (among sire: $\sigma_{\text {Si }}^{2}$ among dam: $\sigma_{\text {Di }}^{2}$ among progeny: $\sigma_{\mathrm{P}}^{2}$ ) were used to calculate the causal variance components (Falconer \& Mackay 1996). The additive genetic variance $\left(V_{\mathrm{A}}\right)$ is 4 times the among-sire variance, i.e. $V_{\mathrm{A}}=4 \sigma^{2} \mathrm{~s}$. The maternal/common environmental variance $\left(V_{\mathrm{M}}\right)$ is $V_{\mathrm{M}}=\sigma_{\mathrm{D}}^{2}-\sigma_{\mathrm{S}}^{2}$, and the residual variance $\left(V_{\mathrm{R}}\right)$ is the among-progeny or within full-sib family variance, i.e. $V_{\mathrm{R}}=\sigma^{2}$. The sum of these 3 components is the total phenotypic variance $\left(V_{\mathrm{P}}\right)$.

We used the among-sire component to estimate $V_{\mathrm{A}}$ because it minimizes potential bias due to dominance and maternal effects included in the among-dam variance component (Falconer \& Mackay 1996). We then estimated the narrow-sense heritability $\left(h^{2}\right)$ following Roff (1997) as:

$$
h^{2}=\frac{V_{\mathrm{A}}}{V_{\mathrm{P}}}=\frac{4 \sigma_{\mathrm{S}}^{2}}{V_{\mathrm{P}}}
$$

Significance of the additive genetic component $\left(V_{\mathrm{A}}\right)$ of each model was assessed by comparing the full model with a reduced model lacking the additive genetic component using a log-likelihood ratio test (Saxton 2004). Determination of SE values of heritability estimates followed protocols described by Roff (1997).

Phenotypic correlations between traits were calculated as Pearson's product-moment correlations using procedure CORR (SAS Institute 2002). Additive genetic correlations, $r_{\mathrm{A}}$, are defined as:

$$
r_{A}=\frac{\mathrm{COV}_{\mathrm{A}}}{\sqrt{V_{\mathrm{A} 1} V_{\mathrm{A} 2}}}
$$

where $\mathrm{COV}_{\mathrm{A}}$ is the covariance between the additive genetic values for the 2 traits and $V_{\mathrm{A} 1}$ and $V_{\mathrm{A} 2}$ are the additive genetic variances for each trait. Significance of the genetic covariance was assessed using a likelihood ratio test (Saxton 2004) by comparing the likelihood of the model containing the genetic covariance component with the reduced model in which the genetic covariance was fixed at 0 .

Throughout this work, we present tables containing several simultaneous statistical tests originating from the same experiment (i.e. $H_{0}: h^{2}=0, H_{0}: r_{\mathrm{A}}=0$ ). To protect against the experimental Type I error, that is, to avoid chance rejection of the null hypothesis when it is in fact true in all cases, correction procedures have been devised, the most popular one being the sequential Bonferroni adjustment (Quinn \& Keough 2002). This correction is based in lowering the critical $\alpha$, which may lead to an increased Type II error rate and result in significant reductions of the power of the tests, particularly in those studies involving many simultaneous comparisons (Moran 2003). Therefore, exploratory studies of heritability face a tradeoff in using as many potentially important traits as possible at the cost of greatly lowering the power of the individual tests to detect significant heritabilities. Also, the Bonferroni correction may not represent a sensible approach for unrelated hypothesis, even if they are not independent (Quinn \& Keough 2002). Unfortunately, there are no clear indications on how to proceed, and researchers choose to either report or not report the Bonferroni correction, while some recommend simply not to apply it in ecological studies (Moran 2003) or to apply some other, less strict alternative (García 2004). In this context, our approach has been to examine as many traits as possible and to report uncorrected individual tests along with their exact $\mathrm{p}$-values.

\section{RESULTS}

\section{Individual variability and phenotypic correlations}

At the constant temperature and food conditions of our study, individual variability was remarkably high. Coefficients of variation (CVs) for life history traits (L, CS and $\left.r_{\max }\right)$ were very high $(27,73$ and $31 \%$ respectively; Table 1). Morphological traits showed less but substantial variation, with CVs ranging between 16 and $23 \%$ (Table 1). Females were significantly larger, had bigger gonads, houses and tails and lived longer than males ( $t$-test: $p<0.01$; Table 2). Sex cannot be identified visually in premature animals; therefore, sexes were not perfectly balanced between families (although a sex ratio of 1:1 was found in this experiment). To avoid loss of power, sex was not included as a factor in the subsequent analyses. In this study, $74 \%$ of males and $60 \%$ of females spawned overnight (data not shown) indicating some degree of diel synchronization.

According to our measured phenotypic correlations, mature appendicularians with longer trunks had big- 
Table 1. Oikopleura dioica. Descriptive statistics of life history and morphological traits. $r_{\max }$ : maximal intrinsic rate of natural increase $\left(\mathrm{d}^{-1}\right)$; L: lifespan $(\mathrm{d})$; $C S_{\text {; }}$ clutch size (eggs female $\left.{ }^{-1}\right)$; ED: egg diameter $(\mathrm{mm})$; TrL: trunk length $(\mathrm{mm})$; GL: gonad length (mm); HS: house size (mm); TL: tail length $(\mathrm{mm})$. Min-Max: minimum and maximum values; \% CV: coefficient of variation; $\mathrm{N}$ : sample size

\begin{tabular}{|lcccc|}
\hline Trait & Mean (SD) & Min-Max & $\% \mathrm{CV}$ & $\mathrm{N}$ \\
\hline$r_{\max }$ & $0.601(0.18)$ & $0.31-1.11$ & 31.0 & 130 \\
L & $8.048(2.17)$ & $4.580-14.17$ & 27.1 & 351 \\
CS & $122.5(87.2)$ & $22.0-644$ & 72.9 & 130 \\
ED & $0.098(0.01)$ & $0.065-0.130$ & 10.9 & 131 \\
TrL & $0.695(0.11)$ & $0.362-1.024$ & 16.2 & 318 \\
GL & $0.465(0.09)$ & $0.192-0.813$ & 19.2 & 318 \\
HS & $3.998(0.92)$ & $1.664-6.893$ & 23.1 & 283 \\
TL & $3.352(0.60)$ & $2.040-5.120$ & 18.2 & 308 \\
\hline
\end{tabular}

ger feeding structures (HS and TL), developed bigger gonads and produced larger clutches (i.e. there were positive correlations between TrL, GL, HS, TL and CS; Table 3). However, longer-lived organisms, which had bigger trunks, houses and tails, developed smaller gonads than shorter-lived appendicularians (Table 2). This suggests that there may be a cost in terms of egg production in organisms that took longer to mature under our experimental conditions. Since longer-lived appendicularians did not produce more eggs, fitness decreased significantly with lifespan (Table 3 ). same environment. However, assuming that the transfer of environmental variance from progeny to dams does not alter the total phenotypic variance (see Eq. 2), this design renders an acceptable estimation of $h^{2}$ based on the sire component of variance (Relyea 2005).

\section{Genetic correlations}

Genetic correlations of lifespan with the other traits matched the phenotypic correlations and were positive with TrL, HS and TL. Longer-lived families had significantly lower fitness than shorter-lived families (Table 4). Correlations between GL and the other traits could not be calculated (Table 3 ) because the estimate of the additive variance component for GL used in the denominator of Eq. (3) was zero (Table 4).

\section{DISCUSSION}

\section{Controlled mating experiments with appendicularians}

This is the first controlled mating experiment conducted on a gelatinous zooplankton species. The experiment has revealed a marked individual variability of important life history traits in the coastal appendicularian Oikopleura dioica. Most importantly, it has

\section{Heritability}

Heritabilities were significant - that is, there were significant additive genetic variances - for $\mathrm{L}$ and $\mathrm{TL}$, and marginally significant for TrL, HS and $r_{\max }\left(\mathrm{p}<0.07\right.$ for $V_{\mathrm{A}}$ component, Table 4). The heritabilities for these traits were high, ranging from 0.37 (trunk length) to 0.89 (lifespan). These values could be biased low because full-sib families were raised in the
Table 3. Oikopleura dioica. Phenotypic (above the diagonal) and genetic (below the diagonal) correlations among traits. Genetic correlations involving GL were not estimated due to its lack of genetic variation. See Table 1 for abbreviations of traits. ${ }^{*} \mathrm{p}<0.05,{ }^{* *} \mathrm{p}<0.01,{ }^{* * *} \mathrm{p}<0.001$

\begin{tabular}{|lccccccc|}
\hline Trait & L & CS & TrL & GL & HS & TL & $r_{\max }$ \\
\hline L & & \multirow{2}{*}{0.001} & $0.345^{* * *}$ & $-0.120^{*}$ & $0.299^{* * *}$ & $0.457^{* * *}$ & $-0.903^{* * *}$ \\
CS & 0.142 & & $0.472^{* * *}$ & $0.743^{* * *}$ & $0.308^{* * *}$ & $0.326^{* * *}$ & $0.427^{* * *}$ \\
TrL & $0.935^{* *}$ & -0.018 & & $0.519^{* * *}$ & $0.706^{* * *}$ & $0.671^{* * *}$ & 0.007 \\
GL & & & & & $0.411^{* * *}$ & $0.361^{* * *}$ & $0.387^{* * *}$ \\
HS & $0.811^{* *}$ & -0.563 & 0.697 & & & $0.618^{* * *}$ & 0.045 \\
TL & $0.996^{* *}$ & -0.200 & $0.917^{*}$ & & $0.797^{*}$ & & $-0.223^{*}$ \\
\hline
\end{tabular}

Table 2. Oikopleura dioica. Descriptive statistics of life history and morphological traits for males and females. Differences between sexes were evaluated with paired $t$-tests (after testing for homogeneity of variances using Levene's test). F:M ratio is the ratio of female and male traits. See Table 1 for abbreviations of traits. ${ }^{*} p<0.05,{ }^{* *} p<0.01,{ }^{* * *} p<0.001$

\begin{tabular}{|c|c|c|c|c|c|c|c|c|c|}
\hline \multirow[b]{2}{*}{ Trait } & \multicolumn{3}{|c|}{ Female } & \multirow[b]{2}{*}{ Mean (SD) } & \multirow{2}{*}{$\begin{array}{l}\text { Male } \\
\quad \% \mathrm{CV}\end{array}$} & \multirow[b]{2}{*}{$\mathrm{N}$} & \multirow{2}{*}{$\begin{array}{l}\mathrm{F}: \mathrm{M} \\
\text { ratio }\end{array}$} & \multirow{2}{*}{$\begin{array}{c}\text { Levene } \\
F\end{array}$} & \multirow{2}{*}{$\begin{array}{c}t \text {-test } \\
t\end{array}$} \\
\hline & Mean (SD) & $\% \mathrm{CV}$ & $\mathrm{N}$ & & & & & & \\
\hline $\mathrm{L}$ & 8.505 (2.18) & 25.6 & 158 & $7.645(2.07)$ & 27.1 & 174 & 1.11 & 0.164 & $-3.609^{* * *}$ \\
\hline $\operatorname{TrL}$ & $0.738(0.11)$ & 14.9 & 147 & $0.658(0.10)$ & 15.2 & 171 & 1.12 & 2.395 & $-6.872^{* * *}$ \\
\hline GL & $0.475(0.10)$ & 21.1 & 142 & $0.457(0.08)$ & 17.5 & 170 & 1.04 & 3.442 & $-1.990^{*}$ \\
\hline $\mathrm{HS}$ & $4.427(0.91)$ & 20.6 & 127 & $3.649(0.78)$ & 21.4 & 156 & 1.21 & 0.071 & $-7.607^{* * *}$ \\
\hline TL & $3.530(0.62)$ & 17.6 & 146 & $3.197(0.55)$ & 17.2 & 161 & 1.10 & 0.959 & $-4.862^{* * *}$ \\
\hline
\end{tabular}


Table 4. Oikopleura dioica. Estimates of additive $\left(V_{\mathrm{A}}\right)$, common environment/maternal $\left(V_{\mathrm{M}}\right)$, residual $\left(V_{\mathrm{R}}\right)$ and phenotypic $\left(V_{\mathrm{P}}\right)$ variance components accompanied by their SE value in round brackets and heritabilities $\left(h^{2}\right)$ for life history and morphological traits. Genetic correlations $\left(r_{\mathrm{A}}\right)$ with fitness $\left(r_{\max }\right)$ are also shown. Significant p-values are in square brackets (ns: not significant).

Numbers in bold text indicate significant and marginally significant values. See Table 1 for abbreviations of traits

\begin{tabular}{|c|c|c|c|c|c|c|}
\hline Trait & $V_{\mathrm{A}}(\mathrm{SE})$ & $V_{\mathrm{M}}(\mathrm{SE})$ & $V_{\mathrm{R}}(\mathrm{SE})$ & $V_{\mathrm{P}}(\mathrm{SE})$ & $h^{2}(\mathrm{SE})$ & $r_{\mathrm{A}}$ \\
\hline$r_{\max }$ & $\begin{array}{c}\mathbf{0 . 0 2 5 3}(0.0258) \\
{[0.070]}\end{array}$ & $\begin{array}{c}0.0116(0.0101) \\
{[\mathrm{ns}]}\end{array}$ & $\begin{array}{c}0.0000(0.013) \\
{[\mathrm{ns}]}\end{array}$ & $\begin{array}{c}0.037(0.008) \\
{[\mathrm{ns}]}\end{array}$ & $\mathbf{0 . 6 9}(0.40)$ & 1.00 \\
\hline $\mathrm{L}$ & $\begin{array}{c}\mathbf{0 . 0 1 4 8}(0.0105) \\
{[0.036]}\end{array}$ & $\begin{array}{c}0.0019(0.0034) \\
{[\mathrm{ns}]}\end{array}$ & $\begin{array}{c}0.0000(0.005) \\
{[\mathrm{ns}]}\end{array}$ & $\begin{array}{c}0.017(0.003) \\
{[\mathrm{ns}]}\end{array}$ & $\mathbf{0 . 8 9}(0.47)$ & $\begin{array}{c}-\mathbf{0 . 9 3} \\
{[0.009]}\end{array}$ \\
\hline CS & $\begin{array}{c}0.0191(0.0189) \\
{[\mathrm{ns}]}\end{array}$ & $\begin{array}{c}0.0000(0.0047) \\
{[\mathrm{ns}]}\end{array}$ & $\begin{array}{c}0.0511(0.013) \\
{[\mathrm{ns}]}\end{array}$ & $\begin{array}{c}0.070(0.008) \\
{[\mathrm{ns}]}\end{array}$ & $0.27(0.32)$ & $\begin{array}{l}0.15 \\
{[\mathrm{~ns}]}\end{array}$ \\
\hline ED & $\begin{array}{c}0.0004(0.0006) \\
{[\mathrm{ns}]}\end{array}$ & $\begin{array}{c}0.0000(0.0002) \\
{[\mathrm{ns}]}\end{array}$ & $\begin{array}{c}0.0020(0.001) \\
{[\mathrm{ns}]}\end{array}$ & $\begin{array}{c}0.002(0.001) \\
{[\mathrm{ns}]}\end{array}$ & $0.18(0.28)$ & $\begin{array}{l}0.62 \\
{[\mathrm{~ns}]}\end{array}$ \\
\hline $\operatorname{TrL}$ & $\begin{array}{c}\mathbf{0 . 0 0 2 0}(0.0016) \\
{[0.068]}\end{array}$ & $\begin{array}{c}0.0001(0.0006) \\
{[\mathrm{ns}]}\end{array}$ & $\begin{array}{c}0.0032(0.001) \\
{[\mathrm{ns}]}\end{array}$ & $\begin{array}{c}0.005(0.001) \\
{[\mathrm{ns}]}\end{array}$ & $\mathbf{0 . 3 7}(0.25)$ & $\begin{array}{c}-\mathbf{0 . 8 7} \\
{[0.047]}\end{array}$ \\
\hline GL & $\begin{array}{c}0.0000(0.0000) \\
{[\mathrm{ns}]}\end{array}$ & $\begin{array}{c}\mathbf{0 . 0 0 1 2}(0.0004) \\
{[0.028]}\end{array}$ & $\begin{array}{c}0.0065(0.001) \\
{[\mathrm{ns}]}\end{array}$ & $\begin{array}{c}0.008(0.001) \\
{[\mathrm{ns}]}\end{array}$ & $0.00(0.08)$ & {$[\mathrm{ns}]$} \\
\hline $\mathrm{HS}$ & $\begin{array}{c}\mathbf{0 . 0 0 4 3}(0.0031) \\
{[0.061]}\end{array}$ & $\begin{array}{c}0.0000(0.0012) \\
{[\mathrm{ns}]}\end{array}$ & $\begin{array}{c}0.0068(0.002) \\
{[\mathrm{ns}]}\end{array}$ & $\begin{array}{c}0.011(0.001) \\
{[\mathrm{ns}]}\end{array}$ & $\mathbf{0 . 3 9}(0.23)$ & $\begin{array}{c}-\mathbf{0 . 9 0} \\
{[0.044]}\end{array}$ \\
\hline $\mathrm{TL}$ & $\begin{array}{c}\mathbf{0 . 0 0 3 3}(0.0022) \\
{[0.019]}\end{array}$ & $\begin{array}{c}0.0000(0.0007) \\
{[\mathrm{ns}]}\end{array}$ & $\begin{array}{c}0.0035(0.001) \\
{[\mathrm{ns}]}\end{array}$ & $\begin{array}{c}0.007(0.001) \\
{[\mathrm{ns}]}\end{array}$ & $\mathbf{0 . 5 0}(0.31)$ & $\begin{array}{l}-0.92 \\
{[0.020]}\end{array}$ \\
\hline
\end{tabular}

shown that part of this variability has a genetic basis and can thus be the subject of natural or artificial selection. The generation time, which facilitates a first-order approximation to fitness (our Eq. 1; Troedsson et al. 2002), has been found to be highly heritable (Table 4). However, we propose 2 notes of caution.

First, mating experiments with appendicularians are extraordinarily time-consuming. Appendicularian cultures require frequent changes of water due to accumulation of discarded filter houses, faeces and excretion products. Efforts to automate the culture conditions (e.g. Bouquet et al. 2009) will help to achieve more ambitious experimental designs. Second, mating experiments involve replication at different levels to extract information on phenotypic variance at each of these levels. In dam-sire experiments, replication occurs at the male, female and offspring levels (Falconer \& Mackay 1996). Variability within full sibs provides the error term for the females, while variability at the female level provides the error term for the males. To ensure independent replication and proper assessment of the error term, individual offspring should be separated from each other, and their experimental chambers (beakers) properly interspersed. In our experiment, it was logistically impossible to isolate each individual in a separate beaker; thus, groups of full sibs were kept together in the same beaker. There could be a potential for life cycle synchronization among full sibs, since they share a common environment (i.e. they may synchronize their spawning to increase fertilization efficiency), thus the among-progeny variance would be decreased while the among-dam variance would be increased. This would lead to an underestimation of the error term and would artificially inflate the power of our test to detect female effects. However, the transfer of environmental variance from progeny to dams would not alter the total phenotypic variance (Eq. 2) and the estimation of the heritability based on the sire component of variance would be acceptable (Relyea 2005).

\section{Sexual dimorphism}

In our experiment, female Oikopleura dioica lived 1.11 times longer than males and had trunks, gonads, filter houses and tails that were 1.12, 1.04, 1.21 and 1.10 times larger, respectively, than those of males (Table 3). Sexual dimorphism is not unknown in appendicularians. Troedsson et al. (2005) found differences in fatty acid composition between sexes probably related to egg development, while Lombard et al. (2009a) detected higher nitrogen content in female gonads but no difference in morphometry. Sexual dimorphism is also common among zooplankton organisms. In calanoid copepods, the female:male ratio is 1.08:1 for the lifespan (Smith \& Lane 1985) and around 1.15:1 for the body size (e.g. Gilbert \& Williamson 1983, Grad \& Maly 1988, Maly \& Maly 1998). Thus, male O. dioica, like copepods, seem to follow the 'live fast, die young' strategy that is common in the animal kingdom (Bonduriansky et al. 2008) and has been explained by differences in the mortality patterns between sexes (Vinogradov 1998). Certainly, predation on $O$. dioica by copepods may be intense (LópezUrrutia 2004) and top-down control is probably an important factor in the regulation of their populations 
(Stibor et al. 2004), but there are no data to support a difference among sexes in mortality patterns. An alternative explanation for the sexual dimorphism in lifespan may relate to differences in reproductive investment. Lombard et al. (2009a) observed that males spawned earlier than females in synchronized cohorts and nitrogen content was higher in female gonads. They suggested that the different protein investment in gamete production may indicate that sperm is less costly to produce than are eggs, and therefore maturation of males may be faster than that of females. Indeed, lifespan was correlated with trunk, house and tail sizes; therefore, females, which lived longer, were bigger than males (Table 2).

In addition, female Oikopleura dioica produced filter houses that were 1.2 times bigger (linear dimension) than those of males (Table 2). If we assume that resource acquisition increases linearly with filter surface (Acuña 2001) and filter surface increases as the second power of its linear dimension, this implies that the female:male filter surface ratio would be ca. 1.5:1, and that females gather 1.5 times more food than do males in the same conditions. Clearly, these aspects of the sexual biology of $O$. dioica deserve further attention. It is worth noting that this is the only dioecious appendicularian; thus, a comparative study may render interesting insights into the origin and limitations of sex in the pelagic realm.

\section{Variability and heritability}

All the studied morphological traits showed high individual phenotypic variability, with CVs ranging from 16.2 to $23.1 \%$ (Table 1 ). This variability is maintained when both sexes are analyzed separately (Table 2). Other studies have highlighted substantial amounts of individual variability for some components of the feeding behaviour in Oikopleura dioica (e.g. Bochdansky \& Deibel 1999, Selander \& Tiselius 2003). High degrees of individual variability in size and activity parameters seem to be a universal phenomenon. Båmstedt (1988) showed a high variability in body size, maturity and physiological activity in natural populations of copepods, which was probably explained by the high environmental variance of the aquatic environment. But he also found that part of this great variability persisted in copepods held under constant laboratory conditions, which he explained by either their nutritional history or inheritance.

Tail length was significantly heritable, but trunk and house size showed marginally significant heritability (Table 4). Among the copepods, the amount of genetic variance in body size seems to depend on the environmental conditions (e.g. McLaren 1976, McLaren \& Cor- kett 1978, Wyngaard 1986b,a), which points to the existence of phenotypic plasticity. This could be the case in appendicularians, where body size has been found to be strongly dependent on temperature or food availability in batch experiments (Troedsson et al. 2002, Lombard et al. 2009a,b). Controlled mating experiments conducted at contrasting environmental conditions should help in deciphering the reaction norms governing size plasticity in appendicularians.

These are the first systematic measurements of HS in an appendicularian under controlled conditions, and their average is slightly smaller than the house diameter of $5 \mathrm{~mm}$ measured by Lohmann (1899) and $5.7 \mathrm{~mm}$ estimated from pictures in Lombard et al. (2010). House size was very variable $(\mathrm{CV}=23 \%)$ but no significant genetic variation was observed, which indicates that this feeding structure is strongly dependent on the environment. An expected result is the correlation between the length of the tail and the size of the house (Table 3). Oikopleura dioica are filter-feeding organisms that move the tail sinusoidally to pump water through the filters of the house (Fenaux 1986). The tail fits the tail chamber in the house to maintain seamless peristaltic pumping function; thus, a genetic correlation between tail length and filter house size is to be expected.

In our experiment, Oikopleura dioica produced on average 122 eggs per female, which is less than 165 reported by Lombard et al. (2009a) under similar food and temperature conditions and well below 303 observed by Troedsson et al. (2002) who used protocols that maximized reproductive output (Bouquet et al. 2009). This suggests that some noncontrolled environmental variable (e.g. pH, salinity) may not have been optimal for egg production during our experiment. No significant genetic variation was observed in gonad or clutch size (Table 4), which indicates that gonad output is strongly dependent on the environment, as suggested by reproductive (Ganot et al. 2007) and life cycle studies (Troedsson et al. 2002). Phenotypic correlations also indicate a clear allometric effect, in which larger females produce significantly bigger gonads and larger clutches, an effect that is already well established for appendicularians (Paffenhöfer 1976). However, our study reveals that a higher reproductive output of larger females does not translate into higher fitness. One reason is that large females are older, as revealed by a positive correlation between $\mathrm{L}$ and $\mathrm{Tr} \mathrm{L}$ (Table 3), thus their larger CS is offset by their longer lifespan. Another reason is that CS is encapsulated within a log term in the numerator of Eq. (1) for the calculation of fitness, while $\mathrm{L}$ is in the denominator without any transformation. Thus, small variations in $\mathrm{L}$ produce relatively large effects on the fitness than do similar variations in CS. 
Oikopleura dioica cultured at a unique food concentration and temperature lived $8.05 \mathrm{~d}$ on average (Table 1), which agrees well with a prediction of $8.5 \mathrm{~d}$ using the ecophysiological model developed by Lombard et al. (2009b) for these particular conditions. However, the lifespan was extremely variable in our experiments, with a range from 4 to $14 \mathrm{~d}$ (Table 1), during which many of the observations were conducted under a variety of food concentrations and temperatures (see Fig. 4 in López-Urrutia et al. 2003; range between 1 and $23 \mathrm{~d}$ ). This trait is also highly heritable. Such genetic variance in a life history trait can only be sustained if the environment is far from equilibrium (e.g. Bell 1997, Hoffmann \& Merila 1999, Byers 2005), otherwise a constant selection pressure will tend to remove variance from that trait, as shown experimentally (e.g. Gustafsson 1986, Mousseau \& Roff 1987, Kruuk et al. 2000) and theoretically (Fisher 1930). Certainly in the planktonic ecosystem, populations of these extremely short-lived organisms often experience rapidly changing conditions within and between generations (Sgró \& Hoffmann 2004). In particular, life prolongation should be advantageous when the resource appears in pulses separated by long time intervals, while a short lifespan would be adaptive for resources that are constant or separated by short time intervals (Carey et al. 2002).

Our fitness estimates were high for a metazoan (average of $0.6 \mathrm{~d}^{-1}$ ). According to Eq. (1), a high intrinsic rate of natural increase can be obtained by increasing the clutch size, or more efficiently, by reducing the lifespan. Organisms that reduce generation time have been termed 'time manipulators', whereas those that increase fecundity are 'clutch manipulators' (Aksnes \& Giske 1990). In this regard, Troedsson et al. (2002) suggest that Oikopleura dioica is a clutch manipulator with a fixed, temperature-dependent generation time and with different oocyte production in response to varying nutrient conditions, which agrees with our observations of high heritability for the lifespan but not for the clutch size.

\section{Genetic selection in appendicularians}

The existence of an important heritable component in some traits opens the door to a rapid microevolutionary response to selection. An undesirable potential consequence is that when choosing organisms for culture experiments, we could be inadvertently selecting some traits that could lead to founder effects and distorted experimental results. For example, one may tend to use the first organisms to mature in the field sample, which may inadvertently lead to selection for shorter-lived parents. These bottleneck selection episodes may have strong effects on the outcome of an experiment. Unfortunately, characteristics of the inocula are rarely reported or controlled in experiments with appendicularians (but see Bouquet et al. 2009).

The extreme phenotypic and the genetic variability highlighted in the present study have important implications. This species inhabits the marine environment, and several key ocean properties are globally changing (Mann et al. 1999, Jones et al. 2001). Predictions of the response of organisms to these changes are usually based on functional responses derived from laboratory experiments (López-Urrutia et al. 2003). However, our results suggest that microevolutionary responses to natural selection should not be neglected. For example, a decrease in predation pressure by copepods or other predators might impose a selection for longer appendicularian lifespan.

Lastly, there is also potential for artificial selection. Our results show the potential of Oikopleura dioica as a model organism for studies of ageing based on selection for short or long lifespan (Spitze 1995).

Acknowledgements. We thank E. López, N. Weidberg, J. Sostres and L. Blanco-Bercial for their assistance during appendicularian sampling. We also thank C. Troedsson for very useful discussions. We are greatly indebted to E. González for her work, comments, questions and excellent help. We thank 3 anonymous reviewers for valuable comments that improved the manuscript. C.M.L. was supported financially by a fellowship from the Spanish Ministry of Education and Science for the improvement of higher education (AP-2004-5310). This research was funded by the Spanish Ministry of Education and Science, under project DINAPROFIT (Dynamics of Winter Phytoplankton Blooms; CTM2006-05588/MAR).

\section{LITERATURE CITED}

Acuña JL (2001) Pelagic tunicates: Why gelatinous? Am Nat 158:100-107

Acuña JL, Kiefer M (2000) Functional response of the appendicularian Oikopleura dioica. Limnol Oceanogr 45: 608-618

Acuña JL, Deibel D, Bochdansky AB, Hatfield E (1999) In situ ingestion rates of appendicularian tunicates in the Northeast Water Polynya (NE Greenland). Mar Ecol Prog Ser 186:149-160

- Aksnes DL, Giske J (1990) Habitat profitability in pelagic environments. Mar Ecol Prog Ser 64:209-215

> Avery DE (2005) Induction of embryonic dormancy in the calanoid copepod Acartia hudsonica: proximal cues and variation among individuals. J Exp Mar Biol Ecol 314: 203-214

Båmstedt U (1988) Ecological significance of individual variability in copepod bioenergetics. Hydrobiologia 167168:43-59

> Beaugrand G, Reid PC, Ibanez F, Lindley JA, Edwards M (2002) Reorganization of the North Atlantic marine copepod biodiversity and climate. Science 296:1692-1694

Beaugrand G, Brander K, Lindley JA, Souissi S, Reid PC (2003) Plankton effect on cod recruitment in the North Sea. Nature 426:661-664 
Bedo AW, Acuña JL, Robins D, Harris RP (1993) Grazing in the micron and the sub-micron particle size range: the case of Oikopleura dioica (Appendicularia). Bull Mar Sci 53:2-14

Bell GAC (1997) Experimental evolution in Chlamydomonas. I. Short-term selection in uniform and diverse environments. Heredity 78:490-497

Bochdansky AB, Deibel D (1999) Functional feeding response and behavioral ecology of Oikopleura vanhoeffeni (Appendicularia, Tunicata). J Exp Mar Biol Ecol 233: 181-211

Bonduriansky R, Maklakov A, Zajitschek F, Brooks R (2008) Sexual selection, sexual conflict and the evolution of ageing and life span. Funct Ecol 22:443-453

Bouquet JM, Spriet E, Troedsson C, Ottera H, Chourrout D, Thompson EM (2009) Culture optimization for the emergent zooplanktonic model organism Oikopleura dioica. J Plankton Res 31:359-370

Bradley BP (1978) Genetic and physiological adaption of the copepod Eurytemora affinis to seasonal temperatures. Genetics 90:193-205

Byers DL (2005) Evolution in heterogeneous environments and the potential of maintenance of genetic variation in traits of adaptive significance. Genetica 123:107-124

> Capitanio FL, Pajaro M, Esnal GB (2005) Appendicularians: an important food supply for the Argentine anchovy Engraulis anchoita in coastal waters. J Appl Ichthyol 21: 414-419

> Carey JR, Liedo P, Harshman L, Liu X, Müller HG, Partridge L, Wang JL (2002) Food pulses increase longevity and induce cyclical egg production in Mediterranean fruit flies. Funct Ecol 16:313-325

Charo-Karisa H, Komen H, Rezk MA, Ponzoni RW, van Arendonk JAM, Bovenhuis H (2006) Heritability estimates and response to selection for growth of Nile tilapia (Oreochromis niloticus) in low-input earthen ponds. Aquaculture 261:479-486

Cushing DH (1990) Plankton production and year-class strength in fish populations: an update of the match/mismatch hypothesis. Adv Mar Biol 26:249-293

Deibel D (1998) Feeding and metabolism of Appendicularia. In: Bone Q (ed) The biology of pelagic tunicates. Oxford University Press, Oxford, p 139-149

> Delsuc F, Brinkmann H, Chourrout D, Philippe H (2006) Tunicates and not cephalochordates are the closest living relatives of vertebrates. Nature 439:965-968

deYoung B, Harris R, Alheit J, Beaugrand G, Mantua N, Shannon L (2004) Detecting regime shifts in the ocean: data considerations. Prog Oceanogr 60:143-164

Ebert D, Yampolsky L, Stearns SC (1993) Genetics of life history in Daphnia magna. I. Heritabilities at two food levels. Heredity 70:335-343

Falconer DS, Mackay TF (1996) Introduction to quantitative genetics. Longman, New York, NY

Fenaux R (1986) The house of Oikopleura dioica (Tunicata, Appendicularia): structure and functions. Zoomorphology 106:224-231

Fenaux R, Gorsky G (1985) Nouvelles techniques d'élevage des appendiculaires. Rapp Comm Int Mer Médit 29: 291-292

Fisher RA (1930) The genetical theory of natural selection. Oxford University Press, Oxford

Flood PR, Deibel D, Morris CC (1990) Visualization of the transparent, gelatinous house of the pelagic tunicate Oikopleura vanhoeffeni using Sepia ink. Biol Bull (Woods Hole) 178:118-125

Ganot P, Bouquet JM, Kallesøe T, Thompson EM (2007) The
Oikopleura coenocyst, a unique chordate germ cell permitting rapid, extensive modulation of oocyte production. Dev Biol 302:591-600

García LV (2004) Escaping the Bonferroni iron claw in ecological studies. Oikos 105:3

Gienapp P, Teplitsky C, Alho JS, Mills JA, Merilä J (2008) Climate change and evolution: disentangling environmental and genetic responses. Mol Ecol 17:167-178

Gilbert JJ, Williamson CE (1983) Sexual dimorphism in zooplankton (Copepoda, Cladocera, and Rotifera). Annu Rev Ecol Syst 14:1-33

Gorsky G, Fenaux R (1998) The role of Appendicularia in marine food webs. In: Bone Q (ed) The biology of pelagic tunicates. Oxford University Press, Oxford, p 161-169

Grad G, Maly EJ (1988) Sex size ratios and their influence on mating success in a calanoid copepod. Limnol Oceanogr 33:1629-1634

> Gustafsson L (1986) Lifetime reproductive success and heritability: empirical support for Fisher's fundamental theorem. Am Nat 128:761-764

> Hairston NG Jr, Dillon TA (1990) Fluctuating selection and response in a population of freshwater copepods. Evolution 44:1796-1805

Hays GC, Richardson AJ, Robinson C (2005) Climate change and marine plankton. Trends Ecol Evol 20:337-344

Hoffmann AA, Merila J (1999) Heritable variation and evolution under favourable and unfavourable conditions. Trends Ecol Evol 14:96-101

Jones PD, Osborn TJ, Briffa KR (2001) The evolution of climate over the last millennium. Science 292:662-667

Kruuk LEB, Clutton-Brock TH, Slate J, Pemberton JM, Brotherstone S, Guinness FE (2000) Heritability of fitness in a wild mammal population. Proc Natl Acad Sci USA 97: 698-703

Littell RC, Milliken GA, Stroup WW, Wolfinger RD (1996) SAS System for mixed models. SAS Institute, Cary, NC

Lohmann H (1899) Das Gehäuse der Appendicularien, sein Bau, seine Funktion und seine Entstehung. Schr Nat Wiss Ver Schlesw-Holst 11:347-407

> Lombard F, Renaud F, Sainsbury C, Sciandra A, Gorsky G (2009a) Appendicularian ecophysiology I. Food concentration dependent clearance rate, assimilation efficiency, growth and reproduction of Oikopleura dioica. J Mar Syst 78:606-616

> Lombard F, Sciandra A, Gorsky G (2009b) Appendicularian ecophysiology II. Modeling nutrition, metabolism, growth and reproduction of the appendicularian Oikopleura dioica. J Mar Syst 78:617-629

Lombard F, Eloire D, Gobet A, Stemmann L, Dolan JR, Sciandra A, Gorsky G (2010) Experimental and modeling evidence of appendicularian-ciliate interactions. Limnol Oceanogr 55:77-90

López-Urrutia A (2004) Predation by calanoid copepods on the appendicularian Oikopleura dioica. Limnol Oceanogr 49:303-307

López-Urrutia A, Acuña JL, Irigoien X, Harris R (2003) Food limitation and growth in temperate epipelagic appendicularians (Tunicata). Mar Ecol Prog Ser 252:143-157

> Maly EJ, Maly MP (1998) Body size and sexual size dimorphism in calanoid copepods. Hydrobiologia 391:171-177

- Mann ME, Bradley RS, Hughes MK (1999) Northern hemisphere temperatures during the past millennium: inferences, uncertainties, and limitations. Geophys Res Lett 26: 759-762

McLaren IA (1976) Inheritance of demographic and production parameters in the marine copepod Eurytemora herdmani. Biol Bull (Woods Hole) 151:200-213 
McLaren IA, Corkett CJ (1978) Unusual genetic variation in body size, development times, oil storage, and survivorship in the marine copepod Pseudocalanus. Biol Bull (Woods Hole) 155:347-359

Mitchell-Olds T (1995) The molecular basis of quantitative genetic variation in natural populations. Trends Ecol Evol 10:324-328

Moran MD (2003) Arguments for rejecting the sequential Bonferroni in ecological studies. Oikos 100:403-405

Mousseau TA, Roff DA (1987) Natural selection and the heritability of fitness components. Heredity 59:181-197

- Neira R, Díaz NF, Gall GAE, Gallardo JA, Lhorente JP, Manterola R (2006) Genetic improvement in coho salmon (Oncorhynchus kisutch). I: Selection response and inbreeding depression on harvest weight. Aquaculture 257:9-17

>ttersen G, Planque B, Belgrano A, Post E, Reid PC, Stenseth NC (2001) Ecological effects of the North Atlantic Oscillation. Oecologia 128:1-14

Paffenhöfer GA (1976) On the biology of Appendicularia of the southeastern North Sea. In: Persoone J, Jaspers E (eds) Population dynamics of marine organisms in relation with nutrient cycling in shallow waters. Proc 10th Eur Mar Biol Symp, Ostend, Belgium, Vol 2. Universa Press, Wetteren, p 437-455

Purcell JE, Sturdevant MV, Galt CP (2005) A review of appendicularians as prey of fish and invertebrate predators. In: Gorsky G, Youngbluth MJ, Deibel D (eds) Response of marine ecosystems to global change: ecological impact of appendicularians. Contemporary Publishing International, Paris, p 359-435

Quinn GP, Keough MJ (2002) Experimental design and data analysis for biologists. Cambridge University Press, Cambridge

Relyea RA (2005) The heritability of inducible defenses in tadpoles. J Evol Biol 18:856-866

Richardson AJ, Schoeman DS (2004) Climate impact on plankton ecosystems in the Northeast Atlantic. Science 305:1609-1612

Roff DA (1997) Evolutionary quantitative genetics. Chapman and Hall, New York, NY

Sato R, Tanaka Y, Ishimaru T (2001) House production by Oikopleura dioica (Tunicata, Appendicularia) under laboratory conditions. J Plankton Res 23:415-423

Saxton A (2004) Genetic analysis of complex traits using SAS. SAS Institute, Cary, NC

Selander E, Tiselius P (2003) Effects of food concentration on the behaviour of Oikopleura dioica. Mar Biol 142:263-270

Editorial responsibility: Inna Sokolova,

Charlotte, North Carolina, USA
Seo HC, Kube M, Edvardsen RB, Jensen MF and others (2001) Miniature genome in the marine chordate Oikopleura dioica. Science 294:2506

> Sgró CM, Hoffmann AA (2004) Genetic correlations, tradeoffs and environmental variation. Heredity 93:241-248

Shaw RG (1987) Maximum-likelihood approaches applied to quantitative genetics of natural populations. Evolution 41: 812-826

Sheridan AK (1997) Genetic improvement of oyster production - a critique. Aquaculture 153:165-179

> Smith SL, Lane PVZ (1985) Laboratory studies of the marine copepod Centropages typicus: egg production and development rates. Mar Biol 85:153-162

> Sommer F, Hansen T, Feuchtmayr H, Santer B, Tokle N, Sommer U (2003) Do calanoid copepods suppress appendicularians in the coastal ocean? J Plankton Res 25:869-871

Spitze K (1993) Population structure in Daphnia obtusa: quantitative genetic and allozymic variation. Genetics 135: $367-374$

Spitze K (1995) Quantitative genetics of zooplankton life histories. Cell Mol Life Sci 51:454-464

Stibor H, Vadstein O, Lippert B, Roederer W, Olsen Y (2004) Calanoid copepod and nutrient enrichment determine population dynamics of the appendicularian Oikopleura dioica: a mesocosm experiment. Mar Ecol Prog Ser 270: 209-215

> Troedsson C, Bouquet JM, Aksnes DL, Thompson EM (2002) Resource allocation between somatic growth and reproductive output in the pelagic chordate Oikopleura dioica allows opportunistic response to nutritional variation. Mar Ecol Prog Ser 243:83-91

Troedsson C, Grahl-Nielsen O, Thompson EM (2005) Variable fatty acid composition of the pelagic appendicularian Oikopleura dioica in response to dietary quality and quantity. Mar Ecol Prog Ser 289:165-176

> Uye S, Ichino S (1995) Seasonal variations in abundance, size composition, biomass and production rate of Oikopleura dioca (Fol) (Tunicata: Appendicularia) in a temperate eutrophic inlet. J Exp Mar Biol Ecol 189:1-11

Vinogradov AE (1998) Male reproductive strategy and decreased longevity. Acta Biotheor 46:157-160

Wyngaard GA (1986a) Heritable life history variation in widely separated populations of Mesocyclops edax (Crustacea: Copepoda). Biol Bull (Woods Hole) 170:296-304

- Wyngaard GA (1986b) Genetic differentiation of life history traits in populations of Mesocyclops edax (Crustacea: Copepoda). Biol Bull (Woods Hole) 170:279-295

Submitted: December 26, 2009; Accepted: November 5, 2010 Proofs received from author(s): January 14, 2011 